\title{
Blue Carbon Stock of the Bangladesh Sundarban Mangroves: What could Be the Scenario after a Century?
}

\author{
Abhra Chanda ${ }^{1} \cdot$ Anirban Mukhopadhyay $^{1}$ (D) Tuhin Ghosh ${ }^{1} \cdot$ Anirban Akhand $^{1}$. \\ Parimal Mondal $^{1}$ - Subhajit Ghosh ${ }^{1} \cdot$ Sandip Mukherjee ${ }^{1} \cdot$ Judith Wolf $^{2}$. \\ Attila N. Lázár ${ }^{3}$ - Md. Munsur Rahman ${ }^{4}$ Mashfiqus Salehin ${ }^{4}$ - S. M. Chowdhury ${ }^{5}$. \\ Sugata Hazra ${ }^{1}$
}

Received: 6 June 2016 / Accepted: 2 September 2016 / Published online: 21 September 2016

(C) The Author(s) 2016. This article is published with open access at Springerlink.com

\begin{abstract}
The total blue carbon stock of the Bangladesh Sundarban mangroves was evaluated and the probable future status after a century was predicted based on the recent trend of changes in the last 30 years and implementing a hybrid model of Markov Chain and Cellular automata. At present 36.24 Tg C and 54.95 Tg C are stored in the above-ground and below-ground compartments respectively resulting in total blue carbon stock of $91.19 \mathrm{Tg} \mathrm{C}$. According to the prediction $15.88 \mathrm{Tg} \mathrm{C}$ would be lost from this region by the year 2115. The low saline species composition classes dominated mainly by Heritiera spp. accounts for the major portion of the carbon sock at present (45.60 $\mathrm{Tg} \mathrm{C}$ ), while the highly saline regions stores only $14.90 \mathrm{Tg} \mathrm{C}$. The prediction shows that after a hundred years almost $22.42 \mathrm{Tg} \mathrm{C}$ would be lost from the low saline regions accompanied by an increase of $8.20 \mathrm{Tg}$ $\mathrm{C}$ in the high saline regions dominated mainly by Excoecaria sp. and Avicennia spp. The net carbon loss would be due to both mangrove area loss $\left(\sim 510 \mathrm{~km}^{2}\right)$ and change in species
\end{abstract}

Electronic supplementary material The online version of this article (doi:10.1007/s13157-016-0819-7) contains supplementary material, which is available to authorized users.

Anirban Mukhopadhyay

anirban_iirs@yahoo.com

1 School of Oceanographic Studies, Jadavpur University, 188 Raja S. C. Mullick Road, Kolkata, West Bengal 700032, India

2 National Oceanography Centre, Joseph Proudman Building, 6 Brownlow Street, Liverpool L3 5DA, UK

3 Department of Engineering and the Environment, University of Southampton, Southampton SO17 1BJ, UK

4 Institute of Water and Flood Management, Bangladesh University of Engineering and Technology (BUET), Dhaka 1000, Bangladesh

5 International Union for Conservation of Nature, Dhaka, Bangladesh composition leading to $58.28 \mathrm{Tg}$ of potential $\mathrm{CO}_{2}$ emission within the year 2115 .

Keywords Blue carbon $\cdot$ Mangroves $\cdot$ Sundarban . Bangladesh $\cdot$ Markov chain $\cdot$ Cellular automata

\section{Introduction}

The ever-increasing greenhouse gas emission (especially $\mathrm{CO}_{2}$ ) due to anthropogenic activities is one of the major challenges the world is facing today (IPCC 2013). Deforestation and land use change is recognized as the second largest source of $\mathrm{CO}_{2}$ to the atmosphere after fossil fuel combustion, which accounts for $12-20 \%$ of the total anthropogenic emissions (van der Werf et al. 2009). As a consequence, mitigation programs like UNFCCC's 'Reducing Emissions from Deforestation and Forest Degradation' (REDD+) have been proposed internationally to secure the carbon locked in natural forest ecosystems and prevent their emission (Donato et al. 2011). In this regard, one of the most important sinks in the global carbon pool, i.e. the organic carbon buried in the mangroves and inter-tidal marshes (commonly referred to as 'blue carbon') has considerably attracted the attention of the present day environmental scientists owing to their promising carbon sequestration potential (McLeod et al. 2011; Hopkinson et al. 2012). This 'blue carbon' can be released to the atmosphere when these coastal ecosystems are converted or degraded. Disturbance or exposure of this organic carbon stock leads to its conversion to species like $\mathrm{CO}_{2}, \mathrm{HCO}_{3}{ }^{-}$, or $\mathrm{CO}_{3}{ }^{2-}$ which in turn affects the ocean-atmosphere equilibrium by either directly injecting $\mathrm{CO}_{2}$ to the atmosphere by means of ocean to atmosphere gas exchange or by reducing the capability of oceans to absorb atmospheric $\mathrm{CO}_{2}$ (Pendleton et al. 2012). 
Amongst the several coastal ecosystems, mangroves are one of the most productive and bio-diverse ecosystems along estuaries, sea coasts and river mouths in the tropical and subtropical intertidal zones. However, the mangroves at the same time are also one of the most highly threatened ecosystems (Hutchison et al. 2014). Almost one-third of world's mangroves have been lost in the past 50 years mainly due to conversion to aquaculture and agricultural fields (Alongi 2002) and this has led many scientists to believe that the entire mangrove community might become extinct by the end of the twenty-first century (Duke et al. 2007). Though the rate of mangrove disappearance seems to have declined in the recent past due to an increase in awareness of the value of mangrove ecosystems (FAO 2007), it is still substantially high enough to be a serious threat to the ecosystem (Kauffman et al. 2014). Due to such a high rate of mangrove loss, the global emissions from mangrove degradation have been estimated to be $0.12 \mathrm{Pg}$ $\mathrm{C} \mathrm{yr}^{-1}$ which accounts for almost $10 \%$ of total carbon emissions from deforestation (Donato et al. 2011). Hence, understanding the spatial dynamics of forest biomass and carbon content is extremely essential in order to develop policies for REDD and similar mitigation efforts (Grabowski and Chazdon 2012).

In view of the importance of carbon content in mangrove ecosystems, the present study was framed on the Bangladesh Sundarban. Several initiatives [like Mitra et al. (2011) and Ray et al. (2011)] were taken to characterize the standing stock of biomass and carbon content in the Indian Sundarban as well. Mukhopadhyay et al. (2015) recently carried out an assessment to characterize the changes in mangrove species assemblages in the Bangladesh Sundarban and predicted the future scenario of species composition. The present study is framed to take the endeavour one step further by assessing the total blue carbon stock of the Bangladesh Sundarban in the year 2115. Based on the changes in species composition that took place in the last two decades and quantifying the present carbon content in the live above-ground and below-ground mangroves along with the soil organic carbon (from the study of Rahman et al. 2015), the future carbon content is predicted by adopting a hybrid methodology of Markov Chain and Cellular Automata modelling.

\section{Materials and Methods}

\section{Study Area}

The Sundarban, a UNESCO World Heritage Site, is the largest single chunk of tidal halophytic mangrove forest of the world (it comprises $3 \%$ of the global mangrove area) which covers approximately an area of $10,000 \mathrm{~km}^{2}$, out of which $60 \%$ is situated in Bangladesh and the rest belongs to India. The present study area under investigation, i.e. Bangladesh Sundarban lies between the latitudes $21^{\circ} 30^{\prime} \mathrm{N}-22^{\circ} 30^{\prime} \mathrm{N}$ and longitudes $89^{\circ} 07^{\prime} \mathrm{E}-89^{\circ} 55^{\prime} \mathrm{E}$ (Fig. 1).

\section{Data Used and Analytical Protocol}

In order to estimate the changes in the species assemblage and future prediction, existing mangrove zonation data for the years 1985 and 1995 were used in the present study. These datasets were prepared by the Bangladesh Forest Department (BFD) by combining exhaustive traditional survey methods with satellite image analysis (Fig. 2). In the recent past, Rahman et al. (2015) carried out a comprehensive assessment of carbon stock throughout the Bangladesh Sundarban by means of a systematic grid sampling method. In this study, the data set prepared by Rahman et al. (2015) has been used (where estimated carbon content in the above-ground, belowground and total blue carbon content in the unit of $\mathrm{Mg} \mathrm{ha}^{-1}$ is provided for the respective species composition classes); however, they derived the total carbon content of the above and below-ground parts of the mangrove trees by multiplying the dry biomass by a factor of 0.5 (based on the assumption that forest biomass roughly contains half carbon by mass according to Gifford (2000)). In order to increase the level of accuracy, the exact carbon concentration in the biomass of the respective species were measured by us to derive the present total carbon stock. The measurement of the above-ground, below-ground and the total blue carbon content of the respective species composition classes for the year 2015 were accordingly revised. In order to effectively merge the carbon content data (by Rahman et al. 2015) and the species composition zonation (developed by BFD), the mangrove forest of Bangladesh Sundarban was broadly classified into 9 species composition classes (Chaffey et al. 1985; Iftekhar and Saenger 2008; Rahman et al. 2015) (Table 1).

With the aid of a geographical information system (GIS) framework the spatial distribution of the respective species composition classes were mapped and the area covered by these classes was measured. Upon multiplying the carbon content data in unit area with the actual area covered by the respective classes, the estimates of total carbon content was derived and their future values were predicted by the MarkovCA model. Earlier studies considered ten species (Chaffey et al. 1985; Iftekhar and Saenger 2008; Rahman et al. 2015), however, the class of 'non tree vegetation' was deliberately excluded from this study. The class of 'non tree vegetation' is diffusely distributed throughout the forest, their spatial variability is not known and their carbon content is negligible when compared to the other mangrove species. Moreover, our aim was to derive an estimate of total carbon stock of the respective species composition according to their areal coverage and since the 'non-tree vegetation' class could not be assigned any particular magnitude in the GIS framework due to its diffused distribution, it was opted out altogether. 


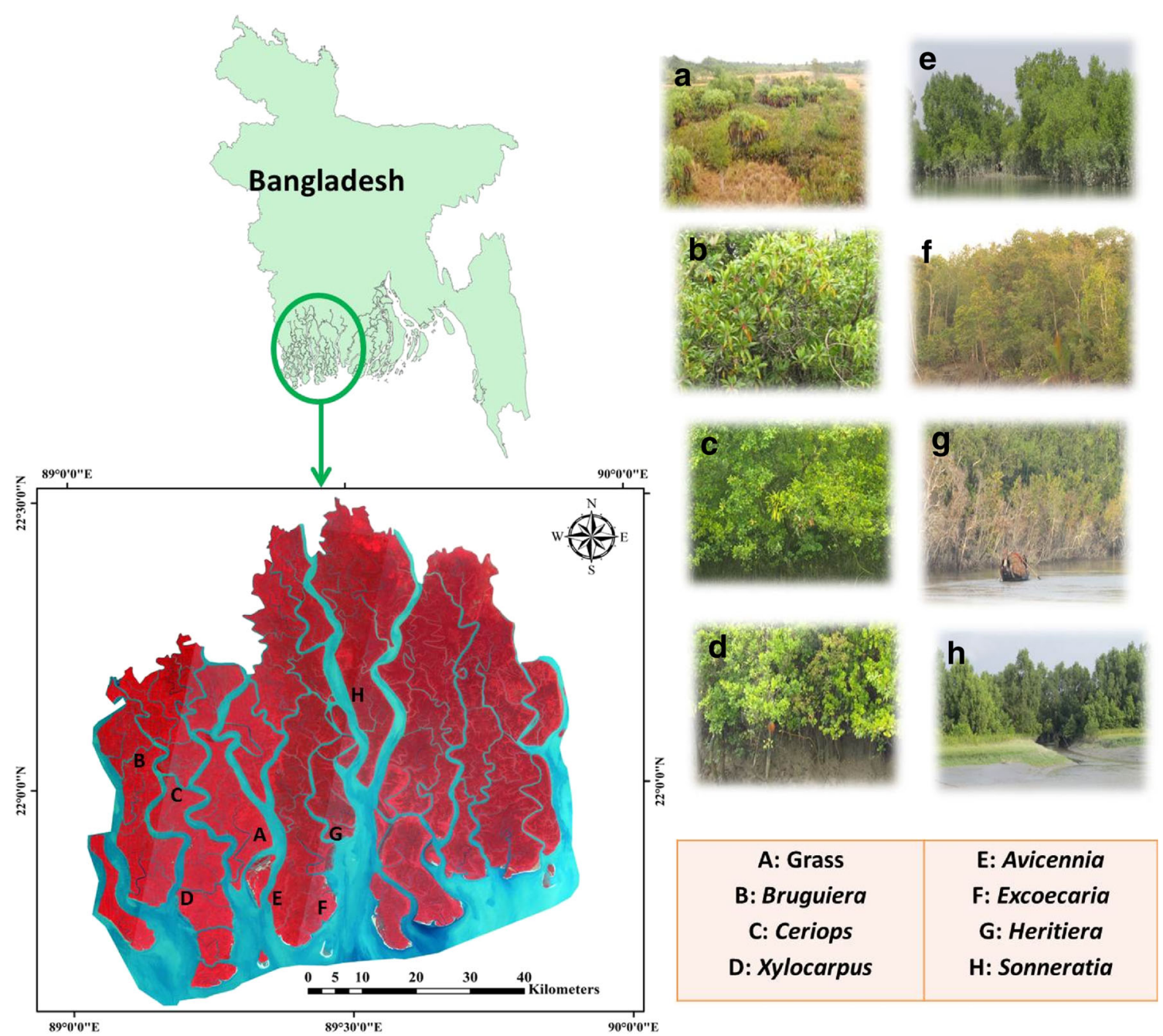

Fig. 1 Study area, Bangladesh Sundarban with the field verification points (A to H)

\section{Carbon Concentration Analysis}

Standard borers (Haglöf, Sweden AB) were used to collect biomass samples from the above-ground stem and trunks as well as below-ground roots of live trees of the respective genus in the sampling sites mentioned in Fig. 1. The samples were oven dried for $72 \mathrm{~h}$ at $85^{\circ} \mathrm{C}$ (until a constant weight was achieved) to obtain the dry weight. 10 replicates of each species were taken in specific quantities and composite samples were prepared for each species from the above mentioned two plant parts. The carbon concentration of the respective plant parts were measured by a CHN analyzer (Perkin Elmer 2400 Series II CHNS/O Elemental Analyzer). See supplementary material Table S1.

\section{Future Prediction and Quantitative Model Development}

All the data of mangrove zonation, spatial biomass distribution and carbon content were converted into a geospatial format. In order to predict the future state of carbon stock in the Bangladesh Sundarban, the Markov Chain model in combination with Cellular Automata (CA) were used. Both Cellular Automata and the Markov Chain model have great advantages in studies related to land use changes (Courage et al. 2009). In the present study, each of the mangrove species assemblages was considered as one land use class and the total Bangladesh Sundarban forest was classified into 9 classes. Implementing the Markov-CA model upon a GIS dataset is believed to be a suitable approach to model the temporal and spatial change of land use (Myint and Wang 2006). In the Markov-CA model, the Markov Chain process helps us analyze the temporal change between the land use types based on transition matrices (Lopeza et al. 2001); whereas the CA model controls spatial pattern change through local rules considering neighbourhood configuration and transition potential maps (Clarke et al. 1994). The GIS environment was used to define the initial conditions, to parameterize the Markov-CA model, to calculate transition matrixes, and to determine the 
Fig. 2. A map showing the distribution of all the nine species composition types for the years (a) 1985 (b) 1995. SC denotes 'species composition'. Refer to Table 1 for the abbreviations of $\mathrm{SC} 1$ to SC9

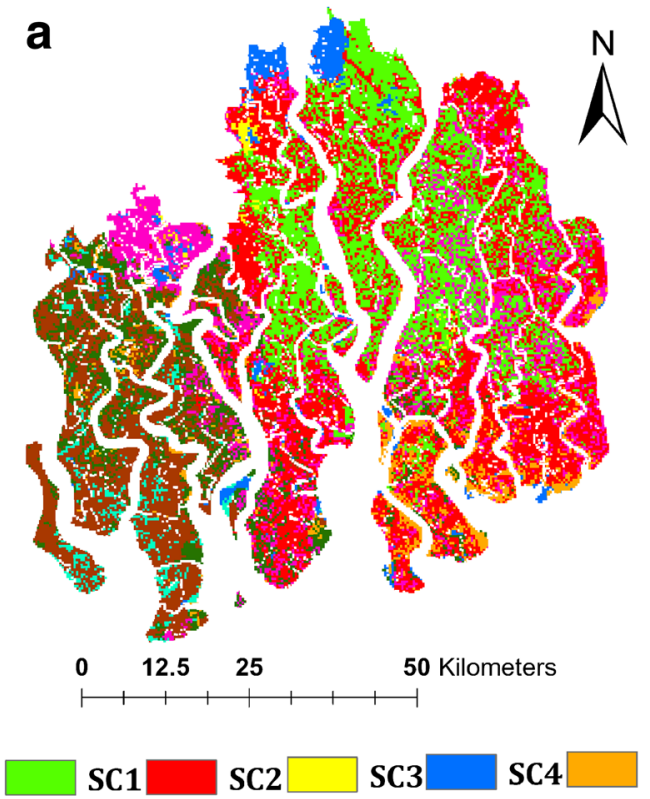

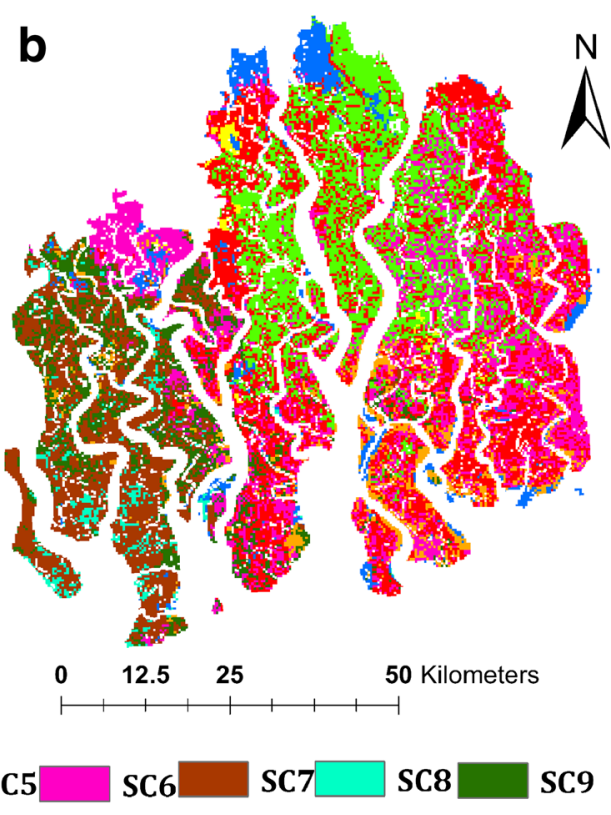

neighbourhood rules (Weng 2002; Aitkenhead and Aalders 2009). Based on the species composition datasets of the year 1985 and 1995, the spatial variability of the species composition in the year 2015 was projected. The carbon content dataset of the respective classes for the year 2015 was fused with this projected data. Finally, based on this merged output, the carbon content of the Bangladesh Sundarban for the year 2035 (after 20 years), 2065 (i.e. 50 years from now) and the year 2115 (i.e. a century from now) was predicted.

\section{Details of Cellular Automata and Markov Chain Modelling}

See Supplementary material (Annexure 1).

\section{Validation of the Model}

In order to validate the quantitative model, the spatial extent of mangrove species zones were predicted for the year 2015 based on the existing datasets of the years 1985 and 1995 . The prediction carried out for the year 2015 was validated against the results of a field survey carried out in 2015 by using Pearson correlation. Special care was taken to cover at least five spots belonging to each species composition class considered in this study. A total of 67 spots were checked and correlated and the ground truthing was carried out especially in those areas where the predicted model output for the year 2015 showed an absence or regeneration of a particular species composition class. Transition probability metrics have been modified for few known classes to increase the accuracy of the model.
Table 1 Major species composition (SC) types considered for this study in the Bangladesh Sundarban along with their distribution pattern in different salinity zones and area covered at present (in the year 2015)

\begin{tabular}{llll}
\hline Code & Species composition type & Distribution in Saline zone & Area (in $\left.\mathrm{km}^{2}\right)^{*}$ \\
\hline SC1 & Heritiera dominated & FR & 602.4 \\
SC2 & Heritiera dominated + Excoecaria & FR, MO, ST & 931.3 \\
SC3 & Mixed Bruguiera, Heritiera and Xylocarpus & FR, ST & 81.5 \\
SC4 & Mixed Avicennia, Bruguiera, Excoecaria, & FR, MO, ST & 192.9 \\
& Sonneratia and Xylocarpus & MO & 204.6 \\
SC5 & Excoecaria dominated & MO, ST & 778.6 \\
SC6 & Excoecaria dominated + Heritiera & MO, ST & 480.2 \\
SC7 & Ceriops dominated + Excoecaria & ST & 69.5 \\
SC8 & Ceriops dominated & MO, ST & 318.2 \\
SC9 & Excoecaria dominated + Ceriops & & \\
\hline
\end{tabular}

FR - fresh water zone, MO - moderate saline zone, and ST- strong saline zone Source (Chaffey et al. 1985; Iftekhar and Saenger 2008; Rahman et al. 2015)

*Area estimated from the present study 


\section{Assumptions Made while Assessing the Future}

The predictive modelling in the present study was carried out taking into account the following assumptions. Firstly, it was assumed that the trend of responsible environmental factors that has driven the changes in species composition and/or carbon content in the live biomass in the recent past would remain the same in the near future. Secondly, it was presumed that the infrastructure of the forest and the biomass content of the trees in terms of age group, along with the height and stature of the trees of respective species would remain unchanged during the following century. Or in other words, it was assumed that the natural cycle of the forest system would not be substantially impacted by any anthropogenic interference like felling of trees of any particular age group, artificial plantations of selected species and so forth. Lastly, it was supposed that no unprecedented cataclysmic event would happen in the coming hundred years as their impact on the forest dynamics was not accounted in the modelling adopted for this study.

\section{Limitations of the Study}

The acceleration rate of the rising sea level was not taken into account in this study. Moreover, the short term sudden impacts of events like tsunami, storm surge and cyclonic disasters were not taken into consideration while running the present CA-Markov model. The entire evaluation was carried out based on the observed changes of the last thirty years and assuming that it will continue to do so in the 'business as usual' mode.

\section{Statistical Analysis}

One sample Kolmogorov-Smirnov test (K-S test) along with Shapiro-Wilk test was performed to verify whether the data of measured carbon content of the respective species is normally distributed. An independent twosample Student's $t$-test was performed to check the significance of the differences in mean between the aboveground and below-ground (measured) carbon content of the respective species. A one-way ANOVA was used to check the significance of the differences in mean carbon content among the seven genera (separately in both the above-ground and below-ground compartments).

\section{Results}

\section{Inter-Genus Carbon Concentration Variation}

The seven dominant genera found to thrive in the Sundarban are namely Avicennia (comprising of three species: Avicennia alba, Avicennia marina and Avicennia officinalis), Bruguiera (comprising of four species: Bruguiera cylindrica, Bruguiera sexangula, Bruguiera gymnorrhiza and Bruguiera parviflora), Ceriops (comprising of two species: Ceriops decandra and Ceriops tagal), Excoecaria (only one species: Excoecaria agallocha), Heritiera (comprising of two species: Heritiera fomes and Heritiera littoralis), Sonneratia (comprising of three species Sonneratia apetala, Sonneratia caseolaris and Sonneratia griffithii) and Xylocarpus (comprising of two species Xylocarpus granatum and Xylocarpus mekongensis). All the above-ground and below-ground carbon concentration data of the respective replicates were normally distributed according to the results of both K-S test and Shapiro-Wilk test $(p>0.05)$. The mean carbon percentage was significantly different among the various genera (in both above-ground and below-ground compartments) (one-way-ANOVA, $p<0.05)$. In the above-ground parts, Excoecaria sp. $(54.8 \%)$ had the highest proportion of carbon followed by Ceriops spp. (53.6\%) and Sonneratia spp. (52.7\%). Whereas in the below-ground roots the highest carbon percentage was observed in Excoecaria sp. (52.6\%) followed by Heritiera sp. (52.4\%), Sonneratia spp. (49.2\%) and Xylocarpus spp. (48.5\%). Taking into account all the genera, the percentage of carbon in the above-ground compartment $(51.8 \%)$ was more than that in the below-ground root systems $(48.9 \%)$. The difference in mean carbon concentration between above-ground and below-ground compartments was found to be statistically significant for all the genera ( $t$ varied from 4.71 to 28.60, $p<0.01$ ). Apart from the genus Heritiera, all the other genera showed a higher carbon proportion in the above-ground section compared to the below-ground root system. In case of Heritiera spp. the below-ground carbon concentration was $2.3 \%$ more than the above-ground. The maximum difference between above- and below-ground carbon concentrations was observed in Ceriops spp. (7.1\%), whereas the least difference was found in Excoecaria spp. (2.2\%). Among the seven dominant genera, except Excoecaria, the rest of the genera have two to three species. It is worth mentioning that the magnitude of carbon concentration did not exhibit any statistically significant intra-genus variability for those genera.

\section{Present State of above-Ground, below-Ground and Total Blue Carbon Content}

The above-ground, below-ground and total blue carbon stock (per unit hectare) of the nine species composition classes reported by Rahman et al. (2015) were revised by incorporating the data of measured carbon concentration and shown in Fig. 3. Comprising the 9 species composition classes an average increase in the carbon content of $3.2 \mathrm{Mg} \mathrm{ha}^{-1}$ and $0.7 \mathrm{Mg} \mathrm{ha}^{-1}$ in the aboveground and belowground compartments were observed compared to that given in Rahman et al. 

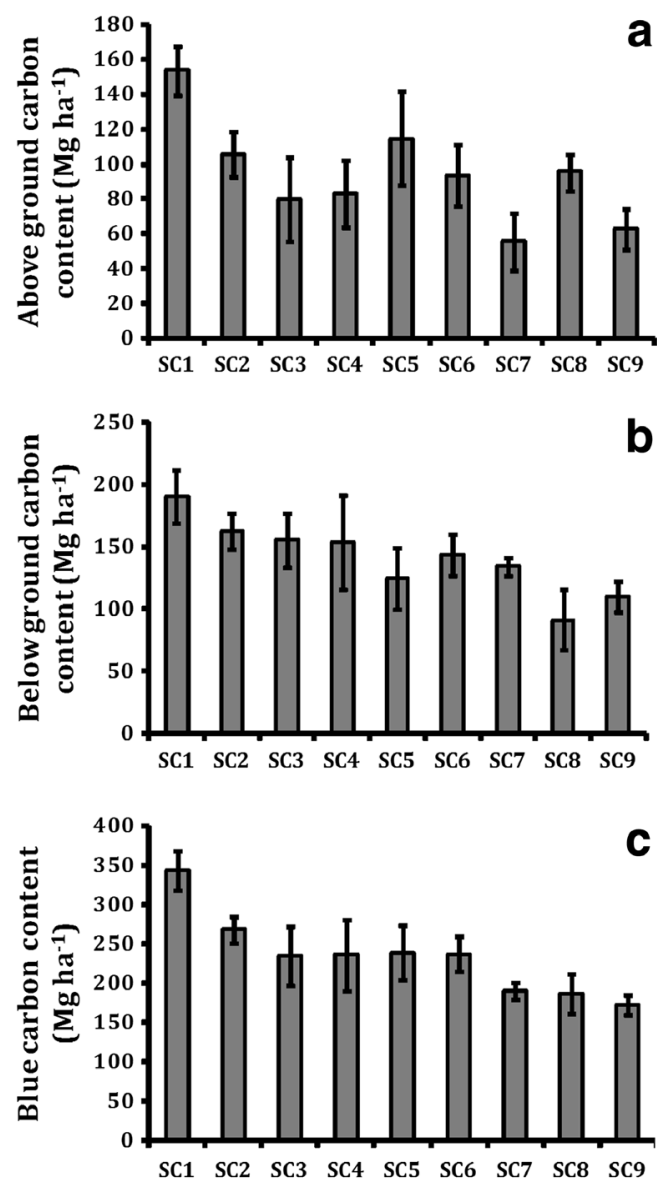

Fig. 3 The revised estimates of (a) above-ground, (b) below-ground and (c) blue carbon content per unit area in the respective species composition classes (principal source of data: Rahman et al. 2015). SC denotes 'species composition'. Refer to Table 1 for the abbreviations of SC1 to SC9

(2015). Among the species composition types, SC1 (i.e. Heritiera dominated class) showed significantly higher $(p<0.05)$ above-ground carbon stock $\left(153.4 \mathrm{Mg} \mathrm{ha}^{-1}\right)$ than other vegetation types, followed by SC5 (i.e. Excoecaria dominated class - $114.3 \mathrm{Mg} \mathrm{ha}^{-1}$ ) and SC2 (i.e. Heritiera dominated + Excoecaria class $-105.6 \mathrm{Mg} \mathrm{ha}^{-1}$ ). The lowest above-ground carbon stock of $55.3 \mathrm{Mg} \mathrm{ha}^{-1}$ was found in SC7 (i.e. Ceriops dominated + Excoecaria class). Like aboveground carbon stock, highest below-ground carbon stock was also found in SC1 (189.6 Mg ha ${ }^{-1}$ ) leading to the highest blue carbon stock of $343.0 \mathrm{Mg} \mathrm{ha}^{-1}$. The second and third highest below-ground carbon stock was found in $\mathrm{SC} 2$ (i.e. Heritiera dominated + Excoecaria class $-162.1 \mathrm{Mg} \mathrm{ha}^{-1}$ ) and SC3 (i.e. Mixed Bruguiera, Heritiera and Xylocarpus class $-154.7 \mathrm{Mg} \mathrm{ha}^{-1}$ ) respectively. The lowest belowground carbon stock was found in SC8 (i.e. Ceriops dominated class $-90.8 \mathrm{Mg} \mathrm{ha}^{-1}$ ). After SC1, SC2 had the second highest blue carbon stock $\left(267.7 \mathrm{Mg} \mathrm{ha}^{-1}\right)$. SC3, SC4, SC5 and SC6 had fairly similar blue carbon stock ranging between 234.1 $\mathrm{Mg} \mathrm{ha}^{-1}$ (SC3) and 238.4 Mg ha ${ }^{-1}$ (SC5). SC7 and SC8 had a blue carbon content of $189.1 \mathrm{Mg} \mathrm{ha}^{-1}$ and 186.1 $\mathrm{Mg} \mathrm{ha}^{-1}$ respectively. SC9 had the lowest blue carbon stock of $172.1 \mathrm{Mg} \mathrm{ha}^{-1}$.

Based on the GIS analysis, it can be seen that the maximum area of the Bangladesh Sundarban forest is at present covered by the class SC2 $\left(931.3 \mathrm{~km}^{2}\right)$, followed by SC6 $\left(778.6 \mathrm{~km}^{2}\right)$, $\mathrm{SC} 1\left(602.4 \mathrm{~km}^{2}\right)$ and $\mathrm{SC} 7\left(480.2 \mathrm{~km}^{2}\right)$ respectively (Fig. 4$)$. The smallest area is covered by SC $8\left(69.5 \mathrm{~km}^{2}\right)$ followed by SC3 $\left(81.5 \mathrm{~km}^{2}\right)$. The estimates of total carbon stored in the above-ground and below-ground of all the SCs were computed (Fig. 5) upon multiplying the area covered by the individual species composition classes with their respective carbon content (per unit area). Owing to a substantially large area covered, SC2 showed the highest total above-ground, total below-ground and total blue carbon stock of $9.84 \mathrm{Tg}, 15.10$
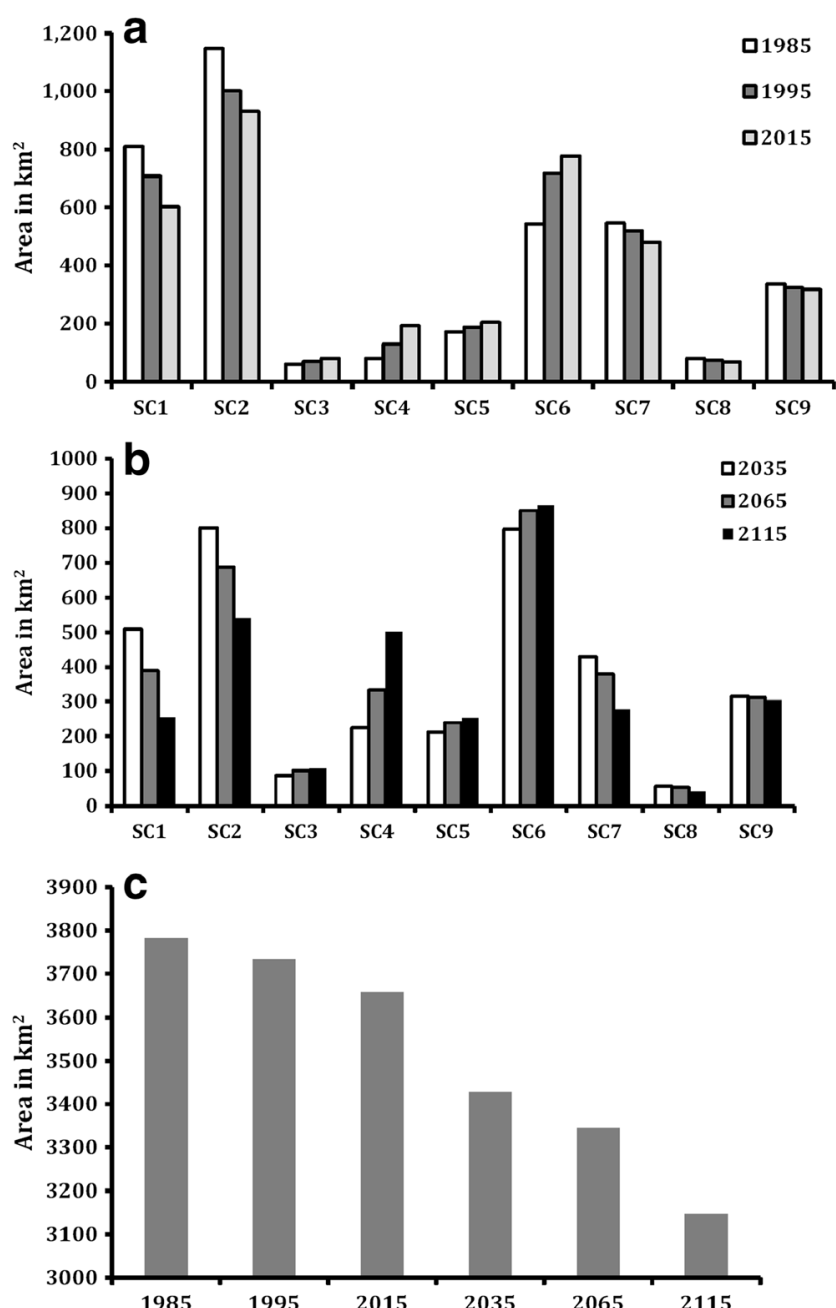

Fig. 4 The figure showing the (a) the trend of change in area covered by respective species composition classes during 1985 to 2015 (b) the predicted change in area covered by respective species composition classes during 2035 to 20,115 and (c) the present (1985 to 2015) and predicted (2035 to 2115) change of total mangrove forest area in the Bangladesh Sundarban. SC denotes 'species composition'. Refer to Table 1 for the abbreviations of SC1 to SC9 
Fig. 5 Present (2015) along with the predicted total carbon content in the above-ground (denoted by AGC), below-ground (BGC) and total blue carbon (TBC) in the respective species composition classes for the years 2035, 2065 and 2115. The total value of carbon content in the respective categories is given within parentheses. All the magnitudes are expressed in $\mathrm{Tg}\left(10^{12} \mathrm{~g}\right)$. SC denotes 'species composition'. Refer to Table 1 for the abbreviations of SC1 to SC9
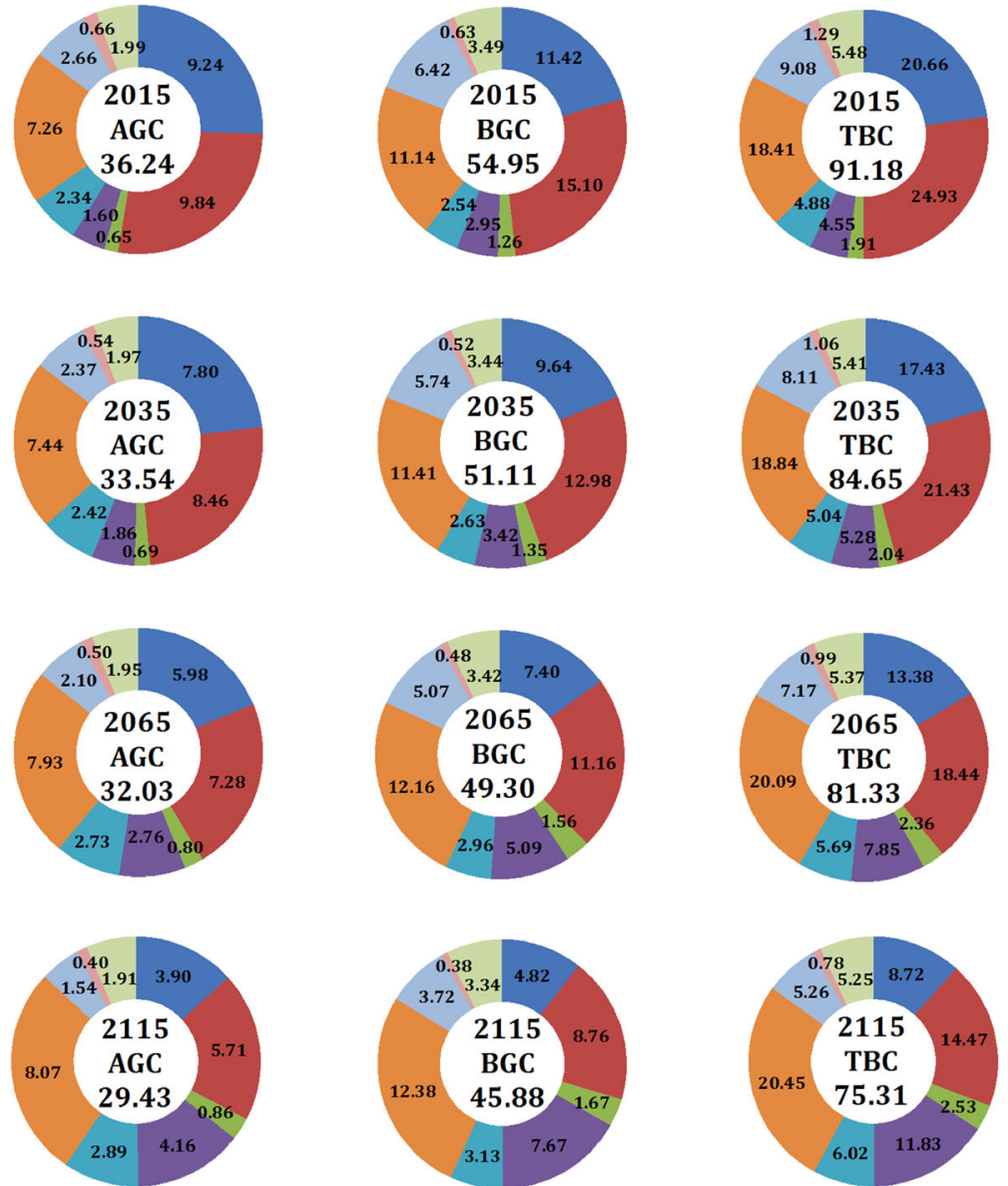

SC1 $\square$ SC2 $\square$ SC3 $\square$ SC4 $\square$ SC5 $\square$ SC6
$\mathrm{Tg}$ and $24.93 \mathrm{Tg}$ respectively. SC1 and SC6 had the second and third highest total above-ground, total below-ground and total blue carbon stock of $9.24 \mathrm{Tg}, 11.42 \mathrm{Tg}, 20.66 \mathrm{Tg}$ and $7.26 \mathrm{Tg}, 11.14 \mathrm{Tg}, 18.41 \mathrm{Tg}$ respectively. The lowest total above-ground carbon stock was found in $\mathrm{SC} 3(0.65 \mathrm{Tg})$, whereas the lowest total below-ground carbon stock was found in SC8 $(0.63 \mathrm{Tg})$. SC8 also showed the lowest total blue carbon stock of $1.29 \mathrm{Tg}$. Summing up the estimates of the respective species composition classes it can be seen that $36.24 \mathrm{Tg} \mathrm{C}$ is locked at present in the above-ground compartments of the Bangladesh Sundarban mangrove forest and $54.95 \mathrm{Tg} \mathrm{C}$ is stored in the below-ground compartments, leading to a total blue carbon stock of $91.19 \mathrm{Tg} \mathrm{C}$ in the entire terrestrial compartment of the forest.

\section{Quantitative Model Validation}

The performance of hybrid model of Markov Chain and Cellular Automata was assessed against 2015 field observations. Ground-truthing was done in selected areas within the coverage of the nine classes and this additional data was used to enhance the accuracy of the model $(88.7 \%)$. Predictions of area change derived from the present model were strongly correlated with observed change over the same period. In order to enhance the degree of accuracy, especially for the planted mangroves and built-up areas, the transition probability table was modified, assuming that these classes will not change significantly with time.

\section{Predictive Model Output}

Based on the spatial datasets for the years 1985, 1995 and 2015 (Fig. 2), the mangrove species composition prediction was done for the years 2035, 2065 and 2115 (Fig. 6). The model showed that the spatial distribution of the nine species composition classes will change significantly and the total forest cover area will decrease substantially in the future. Among the nine species composition classes, the area covered by $\mathrm{SC} 1, \mathrm{SC} 2, \mathrm{SC} 7, \mathrm{SC} 8$ and $\mathrm{SC} 9$ are predicted to decrease in the years to follow, while $\mathrm{SC} 3, \mathrm{SC} 4, \mathrm{SC} 5$ and $\mathrm{SC} 6$ are expected to increase their expanse throughout the forest of Bangladesh Sundarban. Almost $510 \mathrm{~km}^{2}$ of net forest area loss is predicted to take place by the end of the year 2115 
(from $3659.2 \mathrm{~km}^{2}$ at present to $3147.8 \mathrm{~km}^{2}$ by the end of 2115). The two main species composition classes namely $\mathrm{SC} 2$ and $\mathrm{SC} 1$, which have the highest stock of carbon, are expected to suffer from area loss and their total carbon content would decrease from $24.93 \mathrm{Tg}$ and $20.66 \mathrm{Tg}$ (in the year 2015 ) to $14.47 \mathrm{Tg}$ and $8.72 \mathrm{Tg}$ respectively (in the year 2115). On the contrary, significant increase in the total carbon stock is expected to take place in the classes SC4 and SC6 from 4.55 Tg and $18.41 \mathrm{Tg}$ (in the year 2015) to $11.83 \mathrm{Tg}$ and $20.45 \mathrm{Tg}$ respectively (in the year 2115). It is worth mentioning that according to the present model, a century later (in the year 2115), the highest total carbon stock in the above-ground $(8.07 \mathrm{Tg})$, belowground $(12.38 \mathrm{Tg})$ and total blue carbon $(20.45 \mathrm{Tg})$ would be stored by SC6 instead of SC2 at present (in the year 2015). The present analysis shows that within a hundred years, $\mathrm{SC} 1(11.94 \mathrm{Tg})$ would undergo maximum total blue carbon content loss, whereas, maximum gain would be observed in SC4 $(7.28 \mathrm{Tg})$. According to the model, on the whole, the total above-ground carbon content of the forest would decrease from $36.24 \mathrm{Tg}$ (at present) to 33.54 $\mathrm{Tg}$ (by the year 2035), $32.03 \mathrm{Tg}$ (by the year 2065) and finally to $29.43 \mathrm{Tg}$ (by the year 2115), i.e. a total aboveground carbon loss of $6.81 \mathrm{Tg}$ is expected to take place within the coming hundred years. Similarly, total belowground carbon is expected to reduce from $54.95 \mathrm{Tg}$ (at present) to $51.11 \mathrm{Tg}$ (by the year 2035), $49.30 \mathrm{Tg}$ (by the year 2065) and 45.88 (by the year 2115). Thus a $9.07 \mathrm{Tg}$ loss in the total below-ground carbon content of the forest is expected to take place within a century. Combining the two estimates a total blue carbon loss of $15.88 \mathrm{Tg}$ is projected by means of this model by the end of the year 2115 due to both mangrove area loss and change in species composition.
Fig. 6. A map showing the predicted distribution pattern of all the nine species composition types predicted for the years (a) 2015 (b) 2035 and (c) 2065 and (d) 2115. SC denotes 'species composition'. Refer to Table 1 for the abbreviations of SC1 to SC9

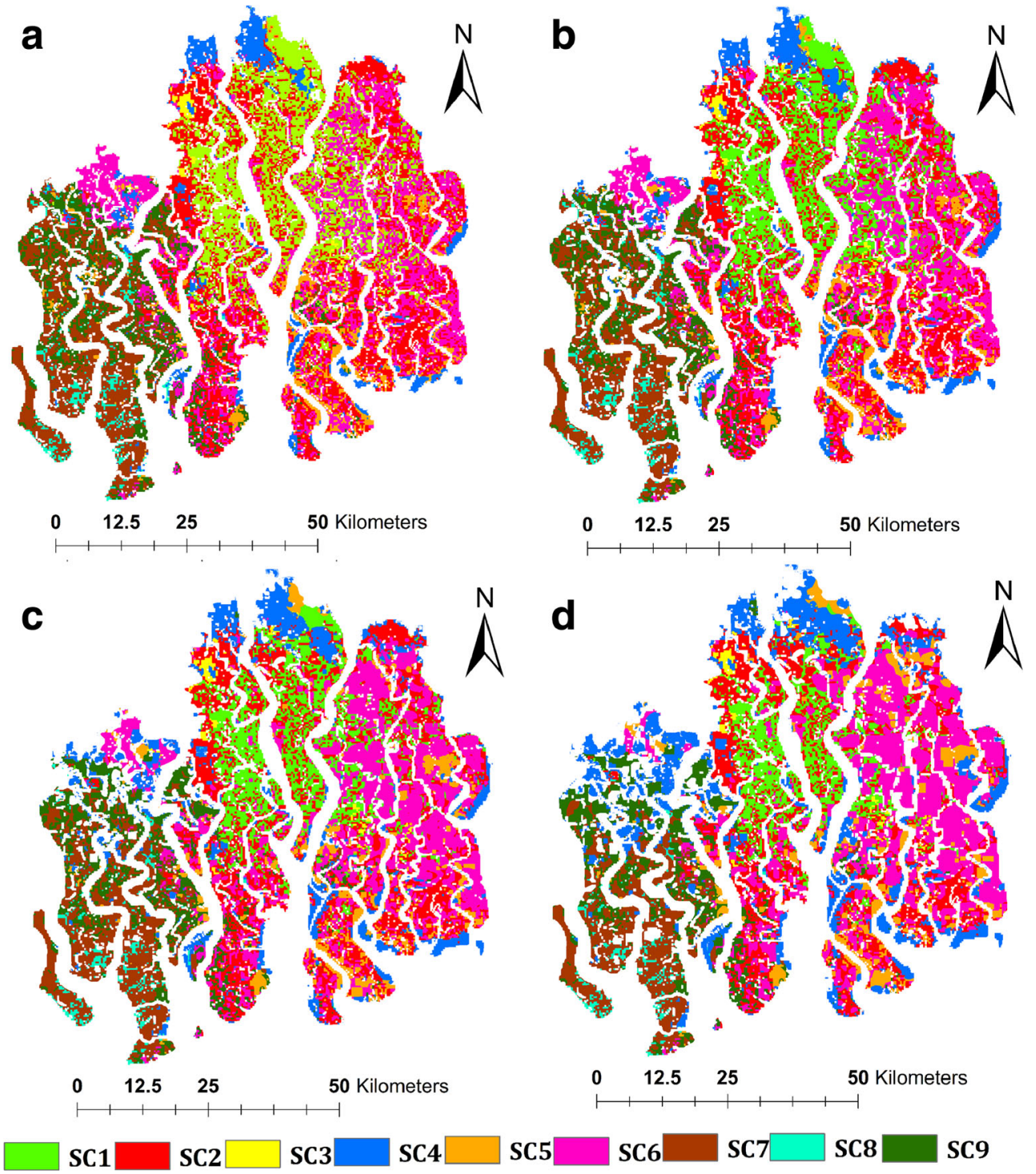


Fig. 7 Map showing different salinity zones of Bangladesh Sundarban (after Hoque et al. 2006)

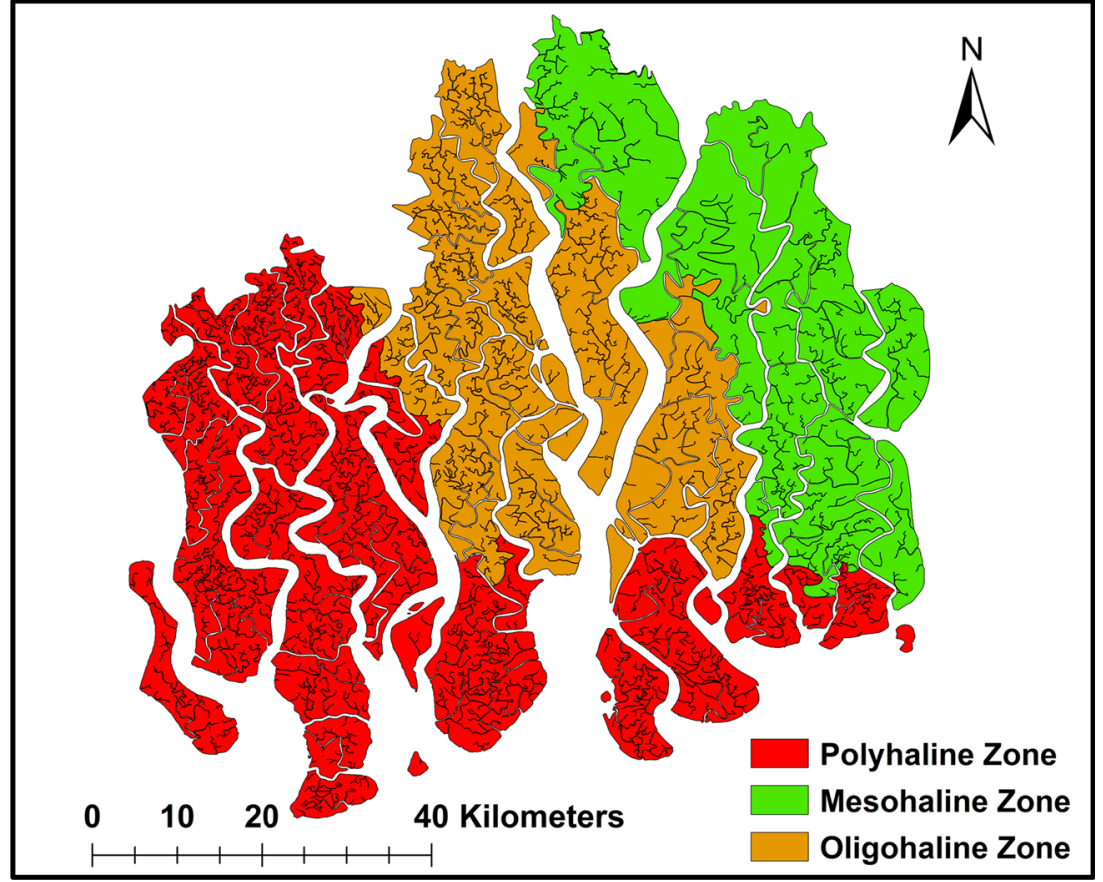

\section{Discussion}

\section{Contrast between above-Ground and below-Ground Carbon Stock}

The results of this study suggest significant differences $(p<0.05)$ in total carbon stock between above-ground and below-ground compartments of all the species composition types. According to the present estimates, total belowground carbon stock is almost 1.5 times more than the total above-ground stock. Rahman et al. (2015) observed that the amount of soil carbon stock was almost similar to total aboveground carbon stock in all the available species assemblages of Bangladesh Sundarban. This implies that irrespective of species composition types, mangroves are capable of storing substantial quantities of organic carbon in their sediments along with the root system (Donato et al. 2011) and together with the carbon locked in the root systems, the total belowground carbon stock always wins the race against the aboveground counterpart (Adame et al. 2013). Moreover, a high root:shoot ratio is found to exist in almost all the dominant species (Fujimoto 2004) which further facilitates these ecosystems to lock larger quantities of carbon below the ground up to great depths (Bouillon et al. 2003).

\section{Distribution and Predicted Loss of Total Carbon from Different Salinity Zones}

The prediction showed that species composition classes dominated by Heritiera sp. and Ceriops spp. would decrease with time, while distribution of Excoecaria sp., Sonneratia spp. and Bruguiera spp. dominated assemblages would increase in the forest. In this regard, it is noteworthy that species like Heritiera sp. is freshwater loving mangroves and prefers to thrive in low saline regions. On the contrary, species like Avicennia sp. and Bruguiera spp. are high salt tolerant species and have the capability of thriving in moderate to high salinity zones (Mukhopadhyay et al. 2015). It has been long recognized by earlier workers that the species distribution or zonation of mangroves are dependent on several controlling factors (Tomlinson 1986; Naskar and Guha Bakshi 1987; Chaudhuri and Choudhury 1994), out of which, salinity profile is one of the most crucial factors (Ellison et al. 2000; Bhattacharjee et al. 2013). The western part of the Sundarban is mainly influenced by high salinity waters (Banerjee et al. 2012), whereas on the eastern side of the Sundarban (especially on the eastern end of the Bangladesh Sundarban) a lower salinity region is known to exist (Islam and Gnauck 2008). The region lying in has a moderate salinity range (Karim 1988). In this regard, Karim (1988) and Hoque et al. (2006) demarcated three different types of salinity zones in the Bangladesh Sundarban, namely: oligohaline (low salinity zone), mesohaline (medium salinity zone) and polyhaline (high salinity zone) regions (Fig. 7). Previous studies indicate that Heritiera prefers to grow in oligohaline regions, whereas Ceriops, Sonneratia and Xylocarpusare generally found in mesohaline regions and species like Avicennia and Excoecaria grow in polyhaline regions (Giri et al. 2014; Naskar and Guha Bakshi 1987; Bhattacharjee et al. 2013; Clough 2013). However, some researchers observed that Avicennia and Excoecaria can thrive over a wide salinity range and Excoecaria was found to grow well even in low 
saline regions (Joshi and Ghose 2003). Based on these observations, the nine species composition classes are classified into three types depending on their salinity zonations. SC1 and SC2 exclusively belong to 'oligohaline' category. Similarly SC3, SC6, SC7 and SC8 belong to the 'mesohaline' category and finally $\mathrm{SC} 4, \mathrm{SC} 5$ and SC9 are grouped under 'polyhaline' category. The above-ground, below-ground and total blue carbon content in these three domains along with the predicted change was computed (Fig. 8). It has been analyzed that at present the total blue carbon stock in the oligohaline class is $45.60 \mathrm{Tg}$ followed by the mesohaline class (30.69
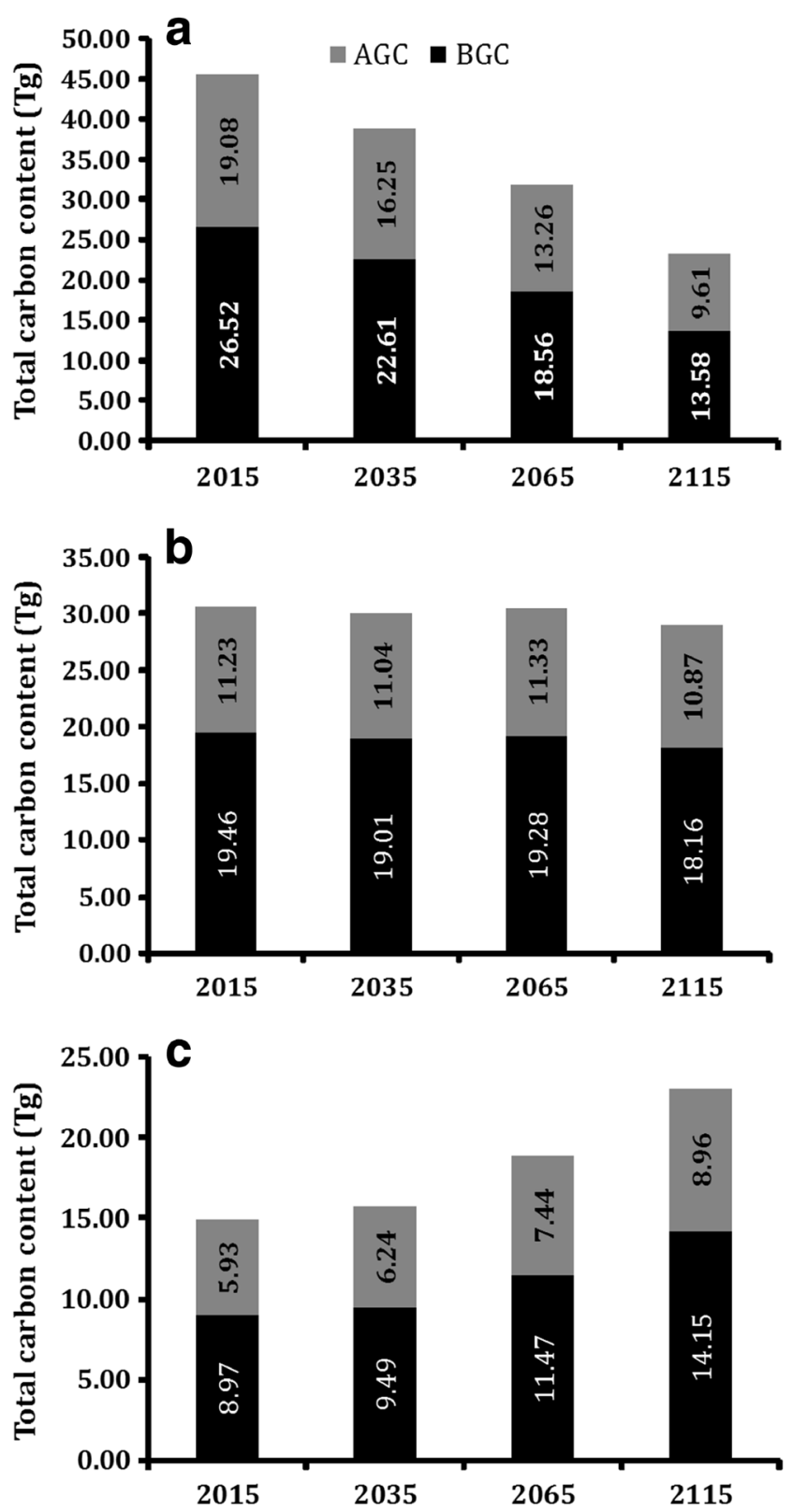

Fig. 8 Total carbon content in the (a) oligohaline, (b) mesohaline and (c) polyhaline zones for the year 2015 and predicted for the years 2035, 2065 and 2115
$\mathrm{Tg}$ ) and it was least in the polyhaline class (14.90 Tg). In this regard, it is worth mentioning that Mitra and Zaman (2015) also observed that freshwater loving mangrove species are capable of storing substantial amount of carbon compared to others. Based on the results of predictive modelling it can be seen that $22.42 \mathrm{Tg}$ of total blue carbon would be lost from the oligohaline class by the year 2115 , while the mesohaline class would not be affected much. On the contrary, total blue carbon content is expected to increase in the polyhaline class by a margin of 8.2 Tg. These results interpret that the low saline species compositions would degrade in future and the abundance of high saline species composition would increase in the same time frame. The decrease in freshwater flow slowly converts the soil character of a particular region into high saline regions (Rahman et al. 2015). In case of mangroves, the distribution of various species assemblages can be explained by virtue of the salinity gradient (Ball 1998) and it also affects the growth, productivity and competitive interactions among species (Sylla et al. 1996; Cardona and Botero 1998; Twilley and Chen 1998). Rahman et al. (2015) observed in the Sundarban that plants show a tendency to become dwarfed with the increase in salinity. Other studies also indicate that chronic high salinity is unfavourable to mangroves (Selvam et al. 1991). On the whole, mangroves flourish well in low saline regions and their productivity as well as carbon stock is found higher in these regions (Kathiresan and Bingham 2001; Crooks et al. 2011). Our present analysis shows that in future the expanse of low salinity preferred species composition would decrease. Though an increase of high salinity preferred class is also noted, the net result would be loss in total blue carbon due to this conversion. Comparative assessments of blue carbon stock in the present study with other mangroves of the world are shown in supplementary material (see Table S2 and Annexure 2).

\section{Predicted Potential $\mathrm{CO}_{2}$ Emission in the Forthcoming Century}

In order to estimate the effect of net forest loss upon the global climate, ecosystem carbon losses are generally expressed as potential $\mathrm{CO}_{2}$ emissions or $\mathrm{CO}_{2}$ equivalents $\left(\mathrm{CO}_{2} \mathrm{e}\right)$ - derived by multiplying the lost carbon stocks by 3.67 , the molecular ratio of $\mathrm{CO}_{2}(44 \mathrm{~g})$ to $\mathrm{C}(12 \mathrm{~g})$ (Kauffman et al. 2014). According to the present estimates almost $58.28 \mathrm{Tg}$ of potential $\mathrm{CO}_{2}$ emission is predicted to take place within the year 2115. Upon dividing the predicted total potential emission with the estimated net area loss of $\sim 510 \mathrm{~km}^{2}$ during the same time frame, $\mathrm{CO}_{2}$ at a mean annual rate of $1121 \mathrm{Mg} \mathrm{ha}^{-1}$ is estimated to be released into the atmosphere from the Bangladesh Sundarban. Pendleton et al. (2012) estimated the global blue carbon emissions and they observed a mean 
potential $\mathrm{CO}_{2}$ emission rate of $0.24 \mathrm{Pg} \mathrm{CO}_{2} \mathrm{yr}^{-1}$ from the global mangrove cover. However, their observed mean amount of $\mathrm{CO}_{2}$ release per unit area for global mangroves (933 $\mathrm{Mg} \mathrm{CO}_{2} \mathrm{ha}^{-1}$ ) was quite less than our estimates predicted for Bangladesh Sundarban for the next century $\left(1121 \mathrm{Mg} \mathrm{CO}_{2}\right.$ $\mathrm{ha}^{-1}$ ). Due to conversion of mangrove lands to shrimp farming, Yee (2010) in Thailand estimated a potential $\mathrm{CO}_{2}$ emission $330 \mathrm{Mg} \mathrm{CO}_{2}$ ha $^{-1}$, whereas, Kauffman et al. (2014) observed potential emissions of 2244 to $3799 \mathrm{Mg} \mathrm{CO}_{2}$ ha $^{-1}$. However, it is of great significance to note that compared to mangroves, estimates of potential $\mathrm{CO}_{2}$ emissions due to conversions of tropical evergreen forests of the Amazon $(538 \mathrm{Mg}$ $\left.\mathrm{CO}_{2} \mathrm{ha}^{-1}\right)$ and the tropical dry forests of Mexico $(230 \mathrm{Mg}$ $\mathrm{CO}_{2} \mathrm{ha}^{-1}$ ) to pastures are much less (Kauffman et al. 2003, 2009). In other words, the $\mathrm{CO}_{2}$ emission arising due to forest conversion and/or loss in a mangrove forest could be five times higher than that in a tropical evergreen forest (Kauffman et al. 2014).

By multiplying the emission with the recent estimate of the global economic cost of new atmospheric carbon of $\$ 41$ per ton of $\mathrm{CO}_{2}$ (2007 U.S. dollars) (USG 2010), Pendleton et al. (2012) further estimated the cost of this carbon emission from mangroves to the global economy (a mean of 9.8 billion US\$ $\mathrm{yr}^{-1}$ ). According to this approach (at the present rate) the cost of predicted blue carbon loss from the Bangladesh Sundarban in the forthcoming century would be equal to 2.26 billion US\$ (though the social cost of carbon is expected to increase in future, hence the estimated cost might turn out higher). According to several schools of thoughts the social cost of carbon (SCC) depends upon the gross domestic product (GDP) of the particular country. In the Indian Sundarban, Akhand et al. (2016) carried out a study and found that Indian Sundarban lost $\sim 64.29$ million US\$ worth blue between the years 1975 and 2013 only from the aboveground compartments.

Combining the field measurements along with data from the literature we quantified the present and predicted the future above-ground, below-ground and total blue carbon stock for a century from now in the Bangladesh Sundarban mangrove forest. An estimated total blue carbon stock of $91.19 \mathrm{Tg}$ (at present) is predicted to be reduced to $75.31 \mathrm{Tg}$ by the year 2115 resulting in a net loss of $15.88 \mathrm{Tg}$ of blue carbon which is equivalent to a potential $\mathrm{CO}_{2}$ emission of $58.28 \mathrm{Tg}$. The major portion of the entire carbon reservoir of this forest is found to be locked in the lower saline regions followed by moderate saline and the least in highly saline zones. The point of concern is that over the passage of time the dominance of freshwater-loving species is predicted to reduce and that of high-salt-tolerant species to increase throughout the forest leading to a substantial loss of blue carbon. These results indicate that the mangroves of the Bangladesh Sundarban play a crucial role in carbon sequestration and this huge carbon reservoir is extremely significant from the perspective of global mangroves. By anticipating the loss of carbon content and changes in species assemblage in these types of studies, the restoration, management and rehabilitation plan for the future should be framed by competent authorities. Thousands of local poor people are dependent on these mangrove forests due to various forest produces like honey, beeswax, fish etc. For a substantial number of people, this forest ecosystem acts as the only source of income, which implies that their livelihood is exclusively dependent on the ecosystem services provided by this forest. This type of study and the outcomes would enable the policy makers to maintain the natural performance of this mangrove ecosystem which in turn would be beneficial to the global climate and this approach might be developed as a wealth-creating instrument under a well-functioning, well-informed market mechanism. However, the predictions carried out in the present study reflect the projection of the present trend in the coming years. In future predictive modelling should be also carried out keeping in view the possible consequences of various other factors like threat from sea level rise and drastic changes in freshwater supply.

Acknowledgments This work has been done under the project 'Assessing Health, Livelihoods, Ecosystem Services and Poverty Alleviation in Populous Deltas [NERC Grant References: NE/J002755/ 1]' which was executed with funding support from the Ecosystem Services for Poverty Alleviation (ESPA) programme. The ESPA programme is funded by the Department for International Development (DFID), the Economic and Social Research Council (ESRC) and the Natural Environment Research Council (NERC). Authors are very grateful to ESPA, DFID, ESRC and NERC. The authors are also grateful to Bangladesh Forest Department (BFD), International Union for Conservation of Nature and Natural Resources (IUCN), Bangladesh and Centre for Environmental and Geographic Information Services (CEGIS), Bangladesh to carry out the present work.

Open Access This article is distributed under the terms of the Creative Commons Attribution 4.0 International License (http:// creativecommons.org/licenses/by/4.0/), which permits unrestricted use, distribution, and reproduction in any medium, provided you give appropriate credit to the original author(s) and the source, provide a link to the Creative Commons license, and indicate if changes were made.

\section{References}

Adame MF, Kauffman JB, Medina I, Gamboa JN, Torres O, Caamal JP, Reza M (2013) Carbon stocks of tropical coastal wetlands within the karstic landscape of the Mexican Caribbean. PLoS One 8:e56569. doi:10.1371/journal.pone.0056569

Aitkenhead MJ, Aalders IH (2009) Predicting land cover using GIS, Bayesian and evolutionary algorithm methods. Journal of Environmental Management 90:236-250

Akhand A, Mukhopadhyay A, Chanda A, Mukherjee S, Das A, Das S, Hazra S, Mitra D, Choudhury SB, Rao KH (2016) Potential CO2 Emission Due to Loss of Above Ground Biomass from the Indian Sundarban Mangroves During the Last Four Decades. Journal of the 
Indian Society of Remote Sensing doi. doi:10.1007/s12524-016$0567-4$

Alongi DM (2002) Present state and future of the world's mangrove forests. Environmental Conservation 29:331-349

Ball MC (1998) Mangrove species richness in relation to salinity and waterlogging: a case study along the Adelaide River floodplain, northern Australia. Global Ecology and Biogeography Letters 7: 73-82

Banerjee K, Chowdhury M, Sengupta R, Sett KS, Mitra A (2012) Influence of anthropogenic and natural factors on the mangrove soil of Indian Sundarban wetland. Archives of environmental. Science 6: $80-91$

Bhattacharjee AK, Zaman S, Raha AK, Gadi SD, Mitra A (2013) Impact of salinity on above-ground biomass and stored carbon in a common mangrove Excoecaria agallocha of Indian Sundarban. The American journal of bio-pharmacology biochemistry and. Life Sciences 2:1-11

Bouillon SM, Frankignoulle F, Dehairs B, Velimirov A, Eiler H, Etcheber G, Borges AV (2003) Inorganic and organic carbon biogeochemistry in the Gautami Godavari estuary (Andhra Pradesh, India) during pre-monsoon: the local impact of extensive mangrove forests. Global Biogeochemical Cycles 17. doi:10.1029/2002GB002026

Cardona P, Botero L (1998) Soil characteristics and vegetation structure in a heavily deteriorated mangrove forest in the Caribbean coast of Colombia. Biotropica 30:24-34

Chaffey DR, Miller FR, Sandom JH (1985) A forest inventory of the Sundarban, Bangladesh. Main report. Overseas Development Administration, England

Chaudhuri AB, Choudhury A (1994) Mangroves of the Sundarban. Vol. I. India, The IUCN Wetlands Programme, Bangkok, IUCN

Clarke KC, Brass JA, Riggan PJ (1994) A cellular-automaton model of wildfire propagation and extinction. Photogrammetric Engineering and Remote Sensing 60:1355-1367

Clough B (2013) Continuing the Journey Amongst Mangroves. ISME Mangrove Educational Book Series No. 1, International Society for Mangrove Ecosystems (ISME), Okinawa, p. 86

Courage K, Masamu A, Bongo A, Munyaradzi M (2009) Rural sustainability under threat in Zimbabwe-simulation of future land use/cover changes in the Bindura district based on the Markov-cellular automata model. Applied Geography 29:435-447

Crooks S, Herr D, Tamelander J, Laffoley D, Vandever J (2011) Mitigating climate change through restoration and management of coastal wetlands and near-shore marine ecosystems: challenges and opportunities. Environment Department Paper 121, World Bank, Washington, DC

Donato DC, Kauffman JB, Murdiyarso D, Kurnianto K, Stidham M, Kanninen M (2011) Mangroves among the most carbon-rich forests in the tropics. Nature Geoscience 4:293-297

Duke NC, Meynecke JO, Dittmann S, Ellison AM, Anger K, Berger U, Cannicci S, Diele K, Ewel KC, Field CD, Koedam N, Lee SY, Marchand C, Nordhaus I, Dahdouh-Guebas F (2007) A world without mangroves? Science 317:41-42

Ellison AM, Mukherjee BB, Karim A (2000) Testing patterns of zonation in mangroves: scale dependence and environmental correlates in the Sundarban of Bangladesh. Journal of Ecology 88:813-824

FAO [Food and Agriculture Organization of the United Nations] (2007) The world's mangroves 1980-2005. FAO Forestry Paper 53. FAO, Rome, Italy. http://www.fao.org/docrep/010/a1427e/a1427e00.htm

Fujimoto K (2004) Below-ground carbon sequestration of mangrove forests in the Asia-Pacific region. In: Vannucci M (ed) Mangrove management and conservation. United Nations University Press, New York, pp. 138-146

Gifford RM (2000) Carbon contents of above-ground tissues of forest and woodland trees. National carbon accounting system technical report no. 22. Australian Greenhouse Office, Canberra
Giri S, Mukhopadhyay A, Hazra S, Mukherjee S, Roy D, Ghosh S, Mitra D (2014) A study on abundance and distribution of mangrove species in Indian Sundarban using remote sensing technique. Journal of Coastal Conservation 18:359-367

Grabowski ZJ, Chazdon RL (2012) Beyond carbon: redefining forests and people in the global ecosystem services market. S.A.P.I.EN.S. [Online], 5.1 (available online since 07 April, 2012). http://sapiens. revues.org/1246. Accessed 18 Sept 2016

Hopkinson CS, Cai W, Hu A (2012) Carbon sequestration in wetland dominated coastal systems - a global sink of rapidly diminishing magnitude. Current Opinions in Environmental Sustainability 4:1-9

Hoque MA, Sarkar MSKA, Khan SAKU, Moral MAH, Khurram AKM (2006) Present status of salinity rise in Sundarban area and its effect on Sundari (Heritiera fomes) species. Research Journal of Agriculture and Biological Sciences 2:115-121

Hutchison J, Manica A, Swetnam R, Balmford A, Spalding M (2014) Predicting global patterns in mangrove forest biomass. Conservation Letters 7:233-240

Iftekhar MS, Saenger P (2008) Vegetation dynamics in the Bangladesh Sundarban mangroves: a review of forest inventories. Wetlands Ecology and Management 16:291-312

IPCC (2013) Summary for Policymakers. In: Climate Change 2013: the physical science basis. In: Stocker TF, Qin D, Plattner GK, Tignor M, Allen SK, Boschung J, Nauels A, Xia Y, Bex V, Midgley PM (eds) Contribution of working group I to the fifth assessment report of the intergovernmental panel on climate change. Cambridge University Press, Cambridge

Islam SN, Gnauck A (2008) Mangrove wetland ecosystems in GangesBrahmaputra delta in Bangladesh. Frontiers of Earth Science in China 2:439-438

Joshi H, Ghose M (2003) Forest structure and species distribution along soil salinity and $\mathrm{pH}$ gradient in mangrove swamps of the Sundarban. Tropical Ecology 44:195-204

Karim A (1988) Environmental factors and the distribution of mangroves in Sundarban with special reference to Heritierafomes, Buch, Ham. Ph.D. thesis, University of Calcutta

Kathiresan K, Bingham BL (2001) Biology of mangrove and mangrove ecosystems. Advances in Marine Biology 40:81-251

Kauffman JB, Steele MD, Cummings DL, Jaramillo VJ (2003) Biomass dynamics associated with deforestation, fire, and conversion to cattle pasture in a Mexican tropical dry forest. Forest Ecology and Management 176:1-12

Kauffman JB, Hughes RF, Heider C (2009) Dynamics of C and nutrient pools associated with land conversion and abandonment in Neotropical landscapes. Ecological Applications 19:1211-1222

Kauffman JB, Heider C, Norfolk J, Payton F (2014) Carbon stocks of intact mangroves and carbon emissions arising from their conversion in the Dominican Republic. Ecological Applications 24:518-527

Lopeza E, Boccoa G, Mendozaa M, Duhau E (2001) Predicting landcover and land-use change in the urban fringe a case in Morelia city, Mexico. Landscape and Urban Planning 55:271-285

McLeod E, Chmura GL, Bouillon S, Salm R, Björk M, Duarte CM, Lovelock CE, Schlesinger WH, Silliman BR (2011) A blueprint for blue carbon: toward an improved understanding of the role of vegetated coastal habitats in sequestering $\mathrm{CO}_{2}$. Frontiers in Ecology and the Environment 9:552-560

Mitra A, Zaman S (2015) Blue carbon reservoir of the blue planet. Springer, New Delhi, pp. 1-299

Mitra A, Sengupta K, Banerjee K (2011) Standing biomass and carbon storage of above-ground structures in dominant mangrove trees in the Sundarbans. Forest Ecology and Management 261:1325-1335

Mukhopadhyay A, Mondal P, Barik J, Chowdhury SM, Ghosh T, Hazra S (2015) Changes in mangrove species assemblages and future prediction of Bangladesh Sundarban using Markov chain model and cellular automata. Environmental Science: Processes and Impacts 17:1111-1117 
Myint SW, Wang L (2006) Multicriteria decision approach for land use land cover change using Markov chain analysis and a cellular automata approach. Canandian Journal of Remote Sensing 32:390 404

Naskar KR, Guha Bakshi DN (1987) Mangrove Swamps of the Sundarban - An Ecological Perspective. Naya Prakash, Calcutta

Pendleton L, Donato DC, Murray BC, Crooks S, Jenkins WA, Sifleet S, Craft C, Fourqurean JW, Kauffman JB, Marbà N, Megonigal P, Pidgeon E, Herr D, Gordon D, Baldera A (2012) Estimating global "blue carbon" emissions from conversion and degradation of vegetated coastal ecosystems. PloS ONE 7(e43542):1-7

Rahman MM, Khan MNI, Hoque AF, Ahmed I (2015) Carbon stock in the Sundarban mangrove forest: spatial variations in vegetation types and salinity zones. Wetlands Ecology and Management 23: 269-283

Ray R, Ganguly D, Chowdhury C, Dey M, Das S, Dutta MK, Mandal SK, Majumder N, De TK, Mukhopadhyay SK, Jana TK (2011) Carbon sequestration and annual increase of carbon stock in a mangrove forest. Atmospheric Environment 45:5016-5024

Selvam V, Mohan R, Ramasubramanian R, Azariah J (1991) Plant communities and soil properties of three mangrove stands of madras coast. Indian Journal of Marine Sciences 20:67-69
Sylla M, Stein A, van Mensvoort MEF (1996) Spatial variability of soil actual and potential acidity in the mangrove agroecosystem of West Africa. Soil Science Society of America Journal 60:219-229

Tomlinson PB (1986) The Botany of Mangroves. Cambridge University Press, Cambridge, p. 413

Twilley RR, Chen R (1998) A water budget and hydrology model of a basin mangrove forest in Rookery Bay, Florida. Marine and Freshwater Research 49:309-323

USG (United States Government) (2010) Technical Support Document: Social Cost of Carbon for Regulatory Impact Analysis Under Executive Order 12866. United States Environmental Protection Agency website. Available at: http://www.epa. gov/otaq/climate/regulations/scc-tsd.pdf

van der Werf GR, Morton DC, DeFries RS, Olivier JGJ, Kasibhatla PS, Jackson RB, Collatz GJ, Randerson JT (2009) $\mathrm{CO}_{2}$ emission from forest loss. Nature Geoscience 2:737-738

Weng QH (2002) Land use change analysis in the Zhujing Delta of China using satellite remote sensing, GIS and stochastic modeling. Journal of Environmental Management 64:273-284

Yee SM (2010) REDD and BLUE carbon: carbon payments for mangrove conservation. MAS capstone project in marine biodiversity and conservation. UCSD 